\title{
FLEXURAL PROPERTIES OF FLAX SLIVER REINFORCED GREEN COMPOSITE BY MOLDING PRESSURE AND CHITOSAN FIBER ADDITION
}

\author{
HIDEAKI KATOGI $^{1} \&$ KENICHI TAKEMURA ${ }^{2}$ \\ ${ }^{1}$ Department of Human Environmental Sciences, Jissen Women's University, Japan \\ ${ }^{2}$ Department of Mechanical Engineering, Kanagawa University, Japan
}

\begin{abstract}
This study investigated the flexural properties of unidirectional flax sliver reinforced polylactic acid by molding pressure and chitosan fiber addition. As a molding condition, the range of molding pressures was $1 \mathrm{MPa}$ to $5 \mathrm{MPa}$. Molding was done using vacuum compression molding. The amount of added chitosan fiber was $5 \mathrm{wt} . \%$. The chitosan fiber was applied to the flax sliver surface. After chitosan fiber addition, the flax sliver surface was observed using scanning electron microscopy (SEM). Static three-point flexural tests of the green composite were conducted at room temperature. As a result, the flexural strength and modulus of green composite increased with increased molding pressure. The flexural strength and the modulus of chitosan fiber with added green composite greatly decreased compared with those of green composite with no added chitosan fiber when the molding pressure was $5 \mathrm{MPa}$. SEM observations revealed many chitosan fibers on the flax sliver surface. The flexural properties of green composites were affected because matrix penetration among the flax fibers readily occurred at molding pressures. However, the flexural properties of the green composite with added chitosan fiber at a molding pressure of $5 \mathrm{MPa}$ was lower than that of the green composite with no added chitosan fiber at a molding pressure of $5 \mathrm{MPa}$ because matrix penetration between flax fibers was probably prevented by the chitosan fiber addition.
\end{abstract}

Keywords: chitosan fiber, green composite, flax sliver, flexural property, molding pressure, polylactic acid.

\section{INTRODUCTION}

The mechanical properties of green composites have been examined for wider application [1]-[11]. The tensile properties of green composites were improved using flax slivers [12]. A green composite was used to form body frames of microelectric vehicles in 2017 [13]. However, interfacial adhesion between natural fibers and the biodegradable polymer was not good. Therefore, the effects of nanofiber addition on the mechanical properties of green composites have been studied for improvement.

Takemura et al. [14] reported the impact properties of a green composite with added cellulose nanofiber using plain woven jute fiber after water immersion. The impact strength of the green composite incorporating plain woven jute fiber was increased by cellulose nanofiber addition to jute fiber surface before and after water immersion. Takagi et al. [15] reported stretching strain effects on the tensile properties of $10 \mathrm{wt} . \%$ cellulose nanofiber added green composite using gel-polyvinyl alcohol. The tensile strength and Young's modulus of a green composite with added cellulose nanofiber increased with increased stretching strain by up to $40 \%$ by fiber orientation control of cellulose nanofiber.

Recently, chitosan fibers found in crab and shrimp shells have been specifically examined as nanofibers for use in the next generation of materials development. The chemical structure of chitosan fiber resembles that of cellulose. However, the effects of molding pressure and chitosan fiber addition on the flexural properties of green composites remain unclear: a fact that limits the wider application of these materials. 
This study investigated the effects of molding pressure and chitosan fiber addition on the flexural properties of a unidirectional flax sliver reinforced green composite.

\section{SPECIMENS}

\subsection{Materials}

The matrix was a PLA resin sheet (Ecodear 250-1B01CA; Toray Co., Ltd.). The reinforcement was done using flax slivers (Shigaasa kogyo Co., Ltd.). The added fiber was chitosan fiber (Bfo-08002; Sugino Machine Limited), 5 wt.\%.

\subsection{Chitosan fiber addition method}

The flax slivers were aligned in a longitudinal orientation. The chitosan fiber was applied to the flax sliver surface on the front and back side. Subsequently, the chitosan fiber with the added flax slivers was dried at room temperature for $24 \mathrm{~h}$ for fabrication of the preform.

\subsection{Molding method and specimen size}

For the fabrication of the green composite, chitosan fiber and PLA sheets, with no added flax slivers, were alternately laminated in the mold. Then, control of flax sliver direction was done using aluminum spacers at both sides on the mold. In addition, the unidirectional preform and PLA sheet were laminated. Vacuum compression molding was used for green composites with and without chitosan fibers and unidirectional flax slivers. The molding pressures were 1.0-5.0 MPa. The molding time was $10 \mathrm{~min}$. The molding temperature was $190^{\circ} \mathrm{C}$. Thereafter, the mold was cooled to room temperature. Fiber volume fractions of green composites with and without added chitosan fiber were 55\%. Their specimen size for static flexural tests was $80 \mathrm{~mm}$ long, $15 \mathrm{~mm}$ wide, and $2.0 \mathrm{~mm}$ thick.

\section{TESTING METHODS}

\subsection{Surface observations of green composites with and without added chitosan fibers}

The surfaces of green composites with and without added chitosan fibers were observed using an optical microscope (VHX-5000; Keyence Co.). From photographs taken at three areas, we measured the fiber orientation angle on the specimen surface. Fig. 1 presents a schematic drawing of fiber orientation angle measurement.

\subsection{Static three-point flexural test}

Static three-point flexural tests of green composites with and without added chitosan fibers were conducted based on Japanese Industrial Standard (JIS) K 7017. The gauge length was $60 \mathrm{~mm}$. The environmental temperature was room temperature. The crosshead speed was $1.0 \mathrm{~mm} / \mathrm{min}$. The number of specimens was five.

\section{RESULTS AND DISCUSSION}

\subsection{Surface observations of flax sliver and green composite}

Fig. 2 portrays the surface of flax sliver after chitosan fiber addition. The surface of chitosan fiber with added flax slivers became rough. Some chitosan fibers were found between flax fibers. The flax sliver surface in some areas was covered by added chitosan fibers. 


\section{Longitudinal direction}

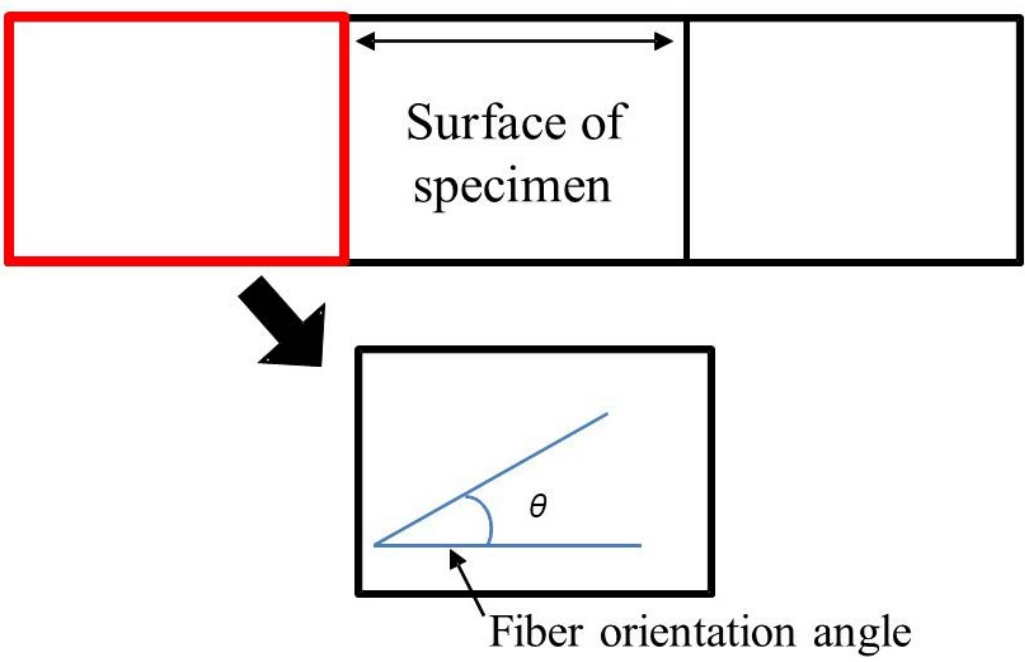

Figure 1: Schematic drawing of fiber orientation angle measurement.

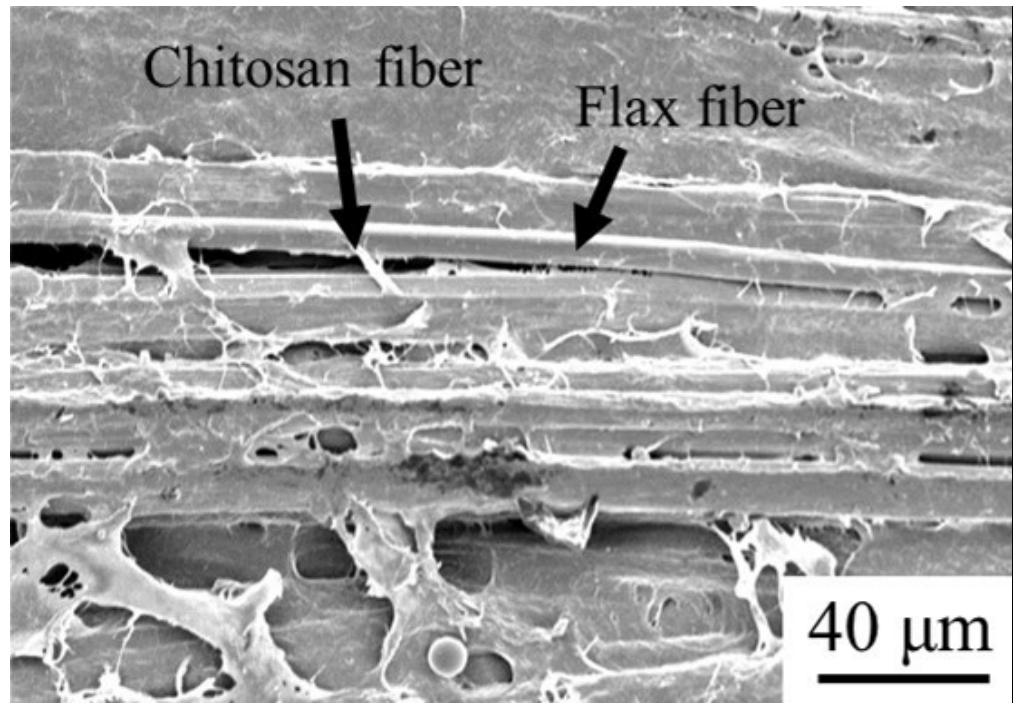

Figure 2: Surface of flax sliver after chitosan fiber addition.

Fig. 3 shows the effects of molding pressure and chitosan fiber on the surface of flax sliver reinforced green composites. Fig. 4 shows the fiber orientation angle on the surface of the flax sliver reinforced green composite. Scattering of fiber orientation angles of green composites under all conditions became small. Fiber orientation angles of green composites were very similar under almost all conditions. Therefore, the flexural properties of the green composite used for this study were unaffected by the fiber orientation angle. 

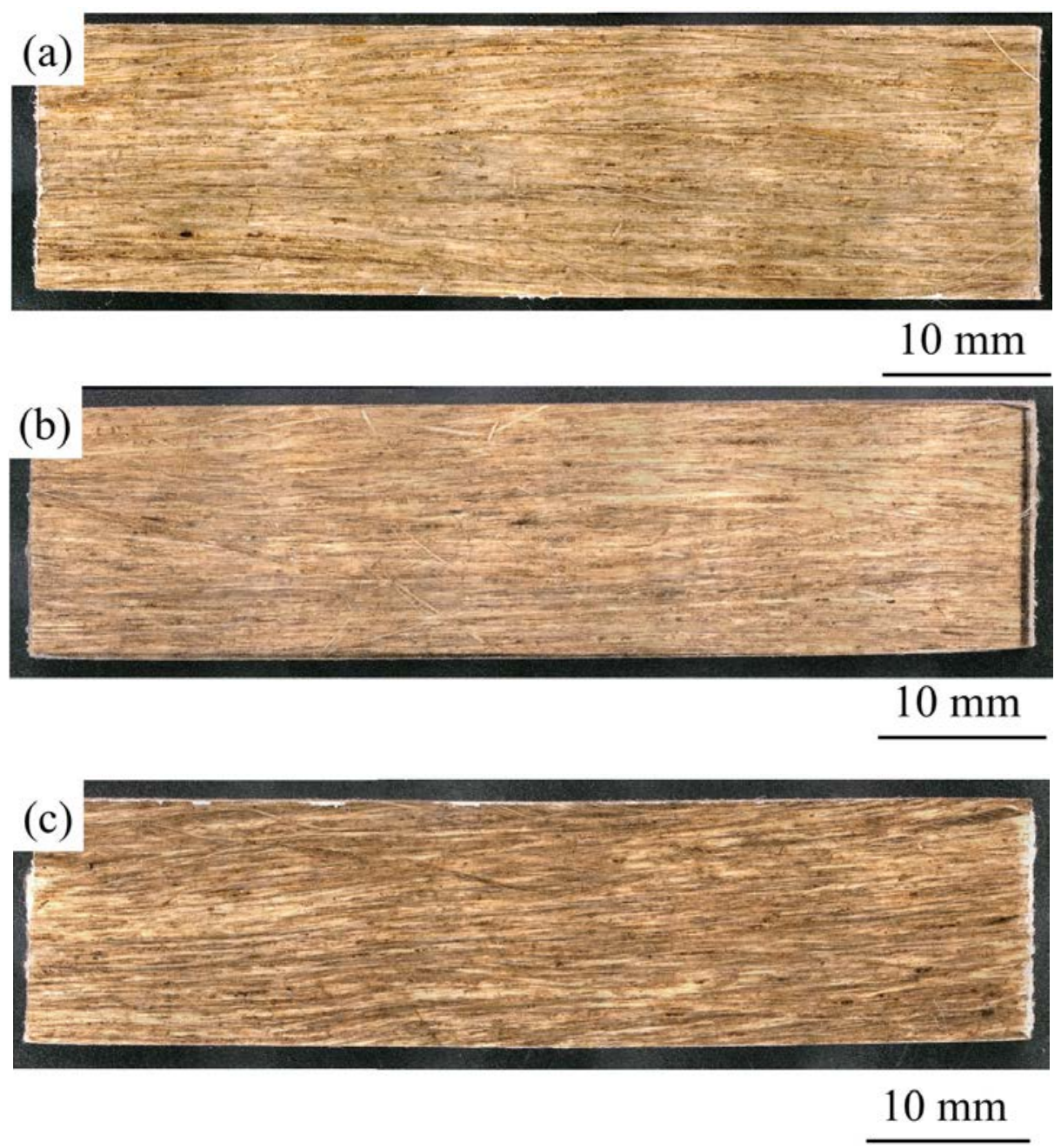

Figure 3: Specimens. (a) Molding pressure $1 \mathrm{MPa}$; (b) Molding pressure $5 \mathrm{MPa}$; and (c) Chitosan fiber addition and molding pressure $5 \mathrm{MPa}$.

\subsection{Static three-point flexural test}

Figs 5 and 6 show the effects of molding pressure and chitosan fiber addition on the flexural properties of the flax sliver reinforced green composite. The flexural strength of green composite increased with increased molding pressure. The flexural strength of the green composite molded at $5 \mathrm{MPa}$ was much greater than that of green composite molded at $3 \mathrm{MPa}$. The flexural modulus of the green composite slightly increased with increased molding pressure up to $3 \mathrm{MPa}$. Subsequently, the flexural modulus of green composite formed at $5 \mathrm{MPa}$ was much higher than that of the green composite molded at $3 \mathrm{MPa}$. However, the flexural strength and modulus of the green composite molded at $5 \mathrm{MPa}$ were decreased $31 \%$ and $30 \%$, respectively, by chitosan fiber addition. 


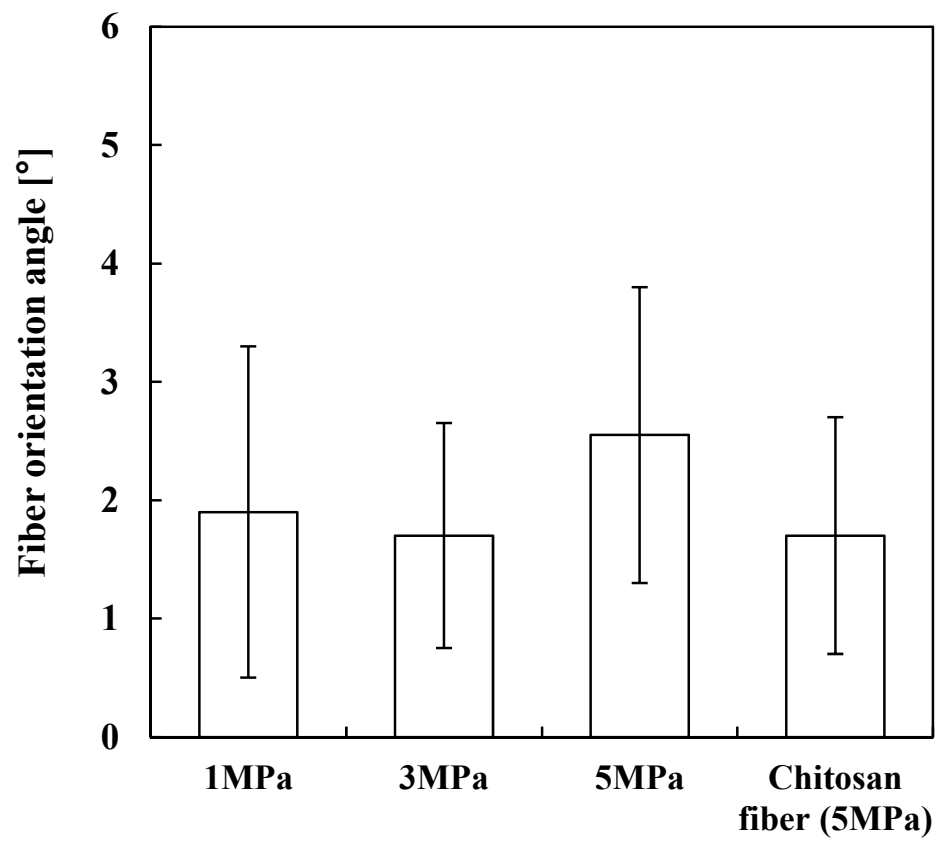

Figure 4: Fiber orientation angle of green composite.

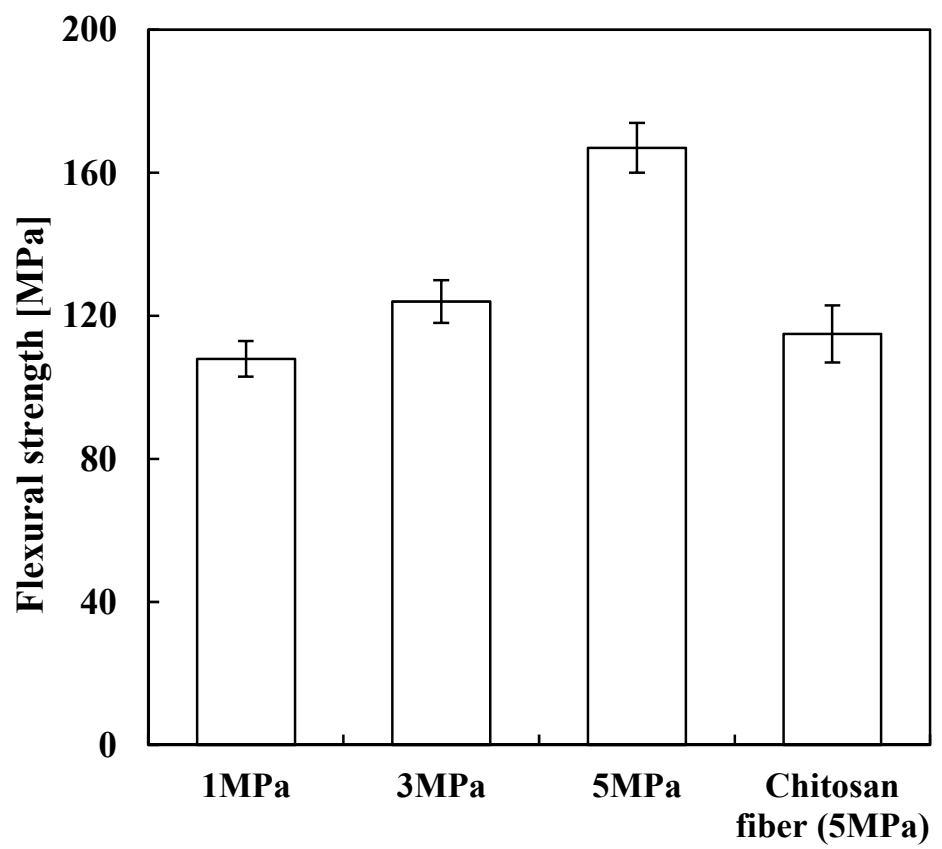

Figure 5: Effects of molding pressure and chitosan fiber addition on flexural strength of green composite. 


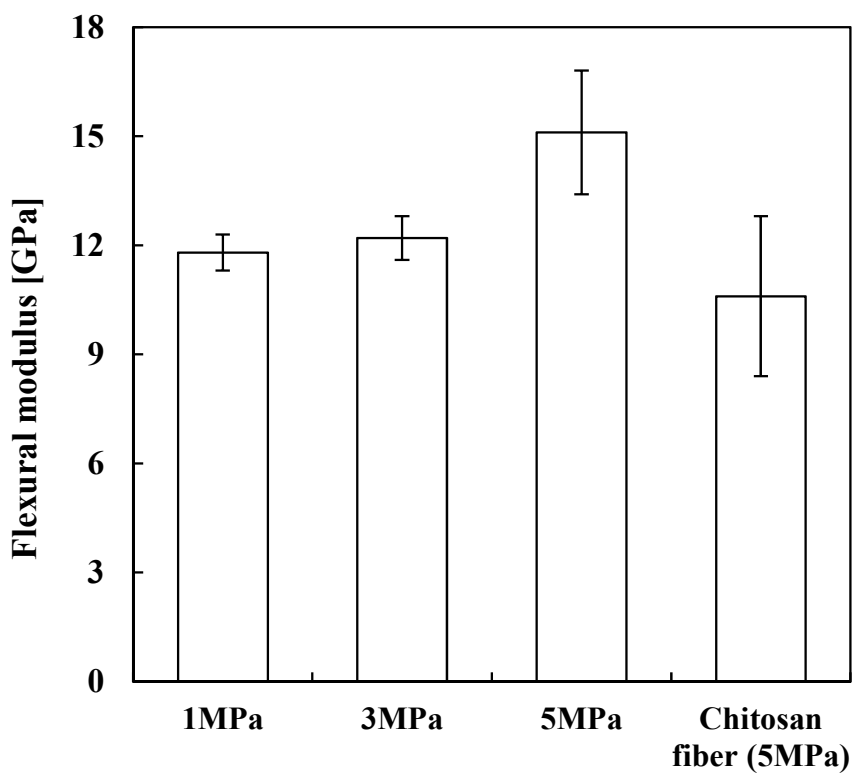

Figure 6: Effects of molding pressure and chitosan fiber addition on flexural modulus of green composite.

The results described above indicate that the fiber orientation angles of green composites were small under all conditions. Moreover, the flax sliver surfaces in some areas were covered by added chitosan fibers (Fig. 2) because chitosan has film-forming ability. When thermogravimetric analysis of chitosan was conducted, the initial temperature of chitosan was about $230^{\circ} \mathrm{C}$ [16]. The matrix was unable to penetrate among flax fibers because of chitosan fibers' film-forming ability and high temperature resistance. Subsequently, many voids formed between flax fibers during molding. Therefore, the flexural property of green composites was unaffected by the fiber orientation angle. The flexural properties of green composites were affected mainly by matrix penetration into flax slivers readily occurring due to molding pressure. By contrast, the flexural properties of green composites with added chitosan fiber molded at $5 \mathrm{MPa}$ decreased because chitosan fiber addition probably prevented matrix penetration among flax fibers.

\section{CONCLUSIONS}

This study investigated the flexural properties of a unidirectional flax sliver reinforced green composite by molding pressure and chitosan fiber addition. The results show that the following conclusions can be drawn.

The flexural strength and modulus of the green composite increased with increased molding pressure. The flexural strength and modulus of the green composite was decreased considerably by chitosan fiber addition when the molding pressure was $5 \mathrm{MPa}$. From surface and SEM observations, fiber orientation angles on surfaces of green composites under all conditions were small. Many chitosan fibers were found on the flax fiber surface. Therefore, the flexural properties of green composites were affected because matrix penetration among the flax fibers occurred easily with adequate molding pressure. However, the flexural properties of green composite formed with added chitosan fiber at $5 \mathrm{MPa}$ 
decreased probably because chitosan fiber addition prevented matrix penetration among the flax fibers.

\section{REFERENCES}

[1] Katogi, H., Shimamura, Y., Tohgo, K. \& Fujii, T., Fatigue behavior of unidirectional jute spun yarn reinforced PLA. Advanced Composite Materials, 21, pp. 1-10, 2012.

[2] Kobayashi, S. \& Takeda, K., Transverse properties of hemp/PLA composite fabricated with micro-braiding technique. Advanced Composite Materials, 24, pp. 509-518, 2015.

[3] Takagi, H., Nakagaito, A.N., Nishimura, K. \& Matsui, T., Mechanical characterisation of nanocellulose composites after structural modification. WIT Transactions on the Built Environment, vol. 166, WIT Press: Southampton and Boston, pp. 335-341, 2016.

[4] Tanaka, K., Shiga, T. \& Katayama, T., Fabrication of hydroxyapatite/PLA composite nanofiber by electrospinning. WIT Transactions on the Built Environment, vol. 166, WIT Press: Southampton and Boston, pp. 371-379, 2016.

[5] Sukmawan, R., Takagi, H. \& Nakagaito, A.N., Strength evaluation of cross-ply green composite laminates reinforced by bamboo fiber. Composites Part B: Engineering, 84, pp. 9-16, 2016.

[6] Wei, L. \& McDonald, A.G., A review on grafting of biofibers for biocomposites. Materials, 9, pp. 303-326, 2016.

[7] Katogi, H., Takemura, K. \& Akiyama, M., Residual tensile property of pain woven jute fiber/poly(lactic acid) green composites during thermal cycling. Materials, 9, pp. 573-583, 2016.

[8] Morreale, M., Mistretta, M.C. \& Fiore, V., Creep behavior of poly(lactic acid) based biocomposites. Materials, 10, pp. 395-407, 2017.

[9] Ullah, S.A.M.M., Shahinur, S. \& Haniu, H., On the mechanical properties and uncertainties of jute yarn. Materials, 10, pp. 450-464, 2017.

[10] Katogi, H. \& Takemura, K., Creep rupture of water-absorbed green composite. WIT Transactions on Engineering Sciences, vol. 116, WIT Press: Southampton and Boston, pp. 281-288, 2017.

[11] Katogi, H., Shimamura, Y., Tohgo, K., Fujii, T. \& Takemura, K., Effect of matrix ductility on fatigue strength of unidirectional jute spun yarns impregnated with biodegradable plastics. Advanced Composite Materials, 27, pp. 235-247, 2018.

[12] Ren, B., Mizue, T., Goda, K. \& Noda, J., Effects of fluctuation of fibre orientation on tensile properties of flax sliver-reinforced green composites. Composite Structures, 94, pp. 3457-3464, 2012.

[13] JEC Group, www.jeccomposites.com/knowledge/international-composites-news/ lina-bio-composite-based-car-pla-honeycomb-sandwich-design.

[14] Takemura, K., Takai, S. \& Katogi, H., Effect of microfibrillated cellulose addition and water absorption on mechanical properties of jute/PLA composites. WIT Transactions on the Built Environment, vol. 124, WIT Press: Southampton and Boston, pp. 387-394, 2012.

[15] Takagi, H., Nakagaito, A.N. \& Sakaguchi, Y., Structural modification of cellulose nanocomposites by stretching. WIT Transactions on Engineering Sciences, vol. 116, WIT Press: Southampton and Boston, pp. 251-256, 2017.

[16] Tsurugai, K. \& Hiraide, T., Preparation and antibacterial activities of NTrimethylammonium salts of chitosan. Sen'i Gakkaishi, 50, pp. 215-220, 1994. (In Japanese.) 